\title{
Anthracycline extravasation injuries: management with dexrazoxane
}

This article was published in the following Dove Press journal:

Therapeutics and Clinical Risk Management

5 May 2009

Number of times this article has been viewed

\author{
Karin Jordan \\ Timo Behlendorf \\ Franziska Mueller \\ Hans-Joachim Schmoll \\ Clinic for Internal Medicine IV, \\ Department for Oncology \\ and Haematology, University \\ Hospital Halle, Halle, Germany
}

\begin{abstract}
The application of anthracyclines in anticancer therapy may result in accidental extravasation injury and can be a serious complication of their use. Tissue necrosis with skin ulceration is a possible outcome in the inadvertent extravasation of anthracyclines during intravenous administration. Until recently, there has been no effective treatment against the devastating effect of extravasated anthracycline. Preclinical and clinical studies are leading to the clinical implementation of dexrazoxane as the first and only proven antidote in anthracycline extravasation. In two multicenter studies dexrazoxane has proven to be highly effective in preventing skin necrosis and ulceration. This review focuses on the development and management of dexrazoxane in anthracycline extravasation injuries.
\end{abstract}

Keywords: dexrazoxane, extravasation, necrosis, anthracyclines

\section{Introduction}

The extravasation of vesicant cancer chemotherapeutic agents, especially anthracyclines, remains one of the most distressing complications that hematologists and oncologists face in cytostatic, intravenous (iv) chemotherapy. Tissue necrosis with skin ulceration is a possible outcome in the inadvertent extravasation of several cytotoxic drugs during iv administration. The management of this complication remains an important challenge in cancer patients. ${ }^{1}$ Several methods including hyperbaric oxygen therapy and different antidotes have been proposed in this setting with the aim to prevent or reduce tissue necrosis. ${ }^{2}$ In July 2006 the EMEA approved dexrazoxane (Savene ${ }^{\circledR}$; TopoTarget A/S, Copenhagen, Denmark) and in September 2007 the FDA approved dexrazoxane (Totect ${ }^{\mathbb{}}$; TopoTarget A/S, Copenhagen, Denmark) for the treatment of extravasation of intranvenous (iv) anthracycline chemotherapy ${ }^{3,4}$ In this paper the management of anthracycline extravasation with dexrazoxane will be reviewed.

\section{Incidence of extravasation}

The estimated incidence of extravasation injuries ranges from $0.1 \%$ to $6 \%{ }^{5,6}$ In a series from the MD Anderson Cancer center the incidence of extravasation ranged between $0.1 \%$ and $1.0 \%$ (44 cases of 40,000 to 60,000 treatments). In these 44 patients, 12 patients suffered from a doxorubicin extravasation.

The implantation of venous access ports is intended to create a safe access to the venous system and thus avoid the likelihood of extravasation. ${ }^{78}$ However, the use of central venous access devices may reduce but does not eliminate the risk of extravasation. ${ }^{9-12}$ Although much safer than peripheral vein access, extravasation may also

submit your manuscript | www.dovepress.cor 
occur when using central venous port catheters with severe complications, eg, mediastinitis. ${ }^{7}$

\section{Classification of vesicant, irritant or non-vesicant chemotherapeutic agents}

Based on their potential for causing local tissue injury, chemotherapeutic agents are classified as vesicant, irritant or non-vesicant. ${ }^{13-17}$

Vesicant drugs have the capability to induce the formation of blisters and/or cause tissue destruction (eg, anthracyclines, amsacrin cisplatin, epirubicin, idarubicin, mitomycin c, mitoxantrone, paclitaxel, vinca alkaloids).

Irritant drugs can cause pain at the injection site or along the vein with or without an inflammatory reaction. Some of these agents have the potential to cause soft tissue ulcers only if a large amount cytotoxic agent solution is extravasated (eg, carboplatin, bendamustine, dacarbacin, docetaxel, etoposide, gemcitabine, ifosfamide, melphalan, topotecan).

Non-vesicant drugs, if extravasated, rarely produce acute reaction of tissue necrosis (eg, asparaginase, bleomycin, cyclophosphamide, cytarabine, fluorouracil, folinic acid, irinotecan, methotrexate, rituximab, thiopeta).

\section{Clinical course of extravasation of vesicant drugs and of anthracyclines}

An anthracycline extravasation is characterized by swelling and redness and is often very painful. Over a period of days or weeks this may progress to tissue necrosis producing tissue sloughing and ulceration with large wounds requiring surgical debridement and/or skin grafts. ${ }^{18-20}$

Anthracyclines can persist in tissues for weeks or even months after extravasation. Furthermore, the local area of extravasation is at high risk of infection, because of both the local necrosis and in general by the impaired immunological state of most patients receiving this kind of treatment. ${ }^{13,21}$ The progression rate to ulceration of significant anthracycline extravasation ranges between $25 \%$ and $50 \%$. $^{22,23}$

The tissue damage may progress over days and weeks, causing pain and increasing the risk of infection, joint destruction, lesions of nerves and permanent dysfunctional and cosmetic changes in the involved area. Even the need for amputating the extremity is possible in case of anthracycline extravasation. $^{24-26}$

\section{Dexrazoxane}

The approval of dexrazoxane was based on efficacy studies conducted in Europe to evaluate dexrazoxane as a post-extravasation treatment. ${ }^{28,29}$ Also several case reports about the successful treatment with dexrazoxane had been published. ${ }^{8,30}$ In summary, in each study the observed treatment frequency and severities of tissue damage appeared to be reduced significantly by dexrazoxane infusions given after anthracycline extravasation.

\section{Chemistry of dexrazoxane}

Dexrazoxane (ICRF-187) can be considered to be a neutral pro-drug analogue to the tetra-acid metal chelator EDTA. Chemically, dexrazoxane is 2,6-piperazinedione,4,4' - (1methyl-1,2-ethanediyl) bis-,(S)- or (S)-(+)-1,2-bis(3,5dioxopiperazin-1-yl)propane. Figure 1 shows the chemical structure.

The molecular formula is $\mathrm{C}_{11} \mathrm{H}_{16} \mathrm{~N}_{4} \mathrm{O}_{4}$; the molecular weight is 268.3. Dexrazoxane is a white to off-white powder, with a melting point of $194 \pm 3^{\circ} \mathrm{C}$. It is soluble in dioxane and $0.1 \mathrm{~N} \mathrm{HCl}$, sparingly soluble in water, tetrahydrofuran, citrate buffer at $\mathrm{pH} 4.0$, phosphate buffer at $\mathrm{pH} 7.0$, and borate-potassium chloride sodium hydroxide buffer at $\mathrm{pH}$ 9.0. The acid dissociation constants, $\mathrm{pKa}$, are 2.5 (for the tertiary piperazine nitrogen) and 9.7 (for the nitrogen imide). The $\log \mathrm{P}$ is -2.135 .

\section{Mechanism of action}

The mechanism by which dexrazoxane diminishes tissue damage resulting from the extravasation of anthracycline drugs is unknown.

However, two ways of action are discussed:

1. Reduction of oxidative stress due to complexes of metal ions and anthracyclines by chelating metal ions

2. Blockade of topoisomerase II poisons by catalytic inhibition of topoisomerase II

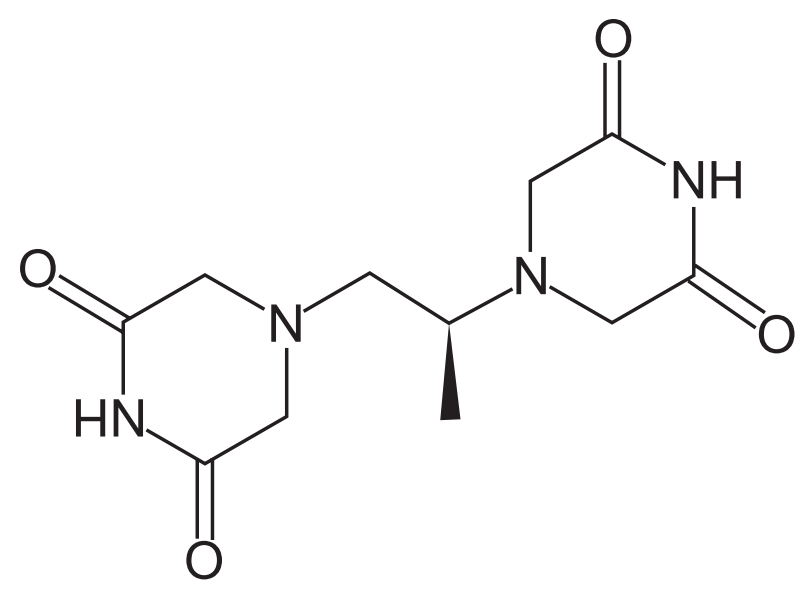

Figure I Chemical structure of dexrazoxane. 
Dexrazoxane is able to penetrate the cell membrane and is degraded to ADR-925 by intracellular hydrolysis. ADR-925 is a strong chelating agent, which is able to form stabile complexes with iron, copper and other metal ions and also able to remove metal ions from complexes of doxorubicin and these ions. ${ }^{31,32}$ If oxidative stress caused by metal ions is assumed to cause tissue damage in anthracycline extravasation, chelating agents such as ADR-925 or EDTA should be able to reduce the level of damage after extravasation. In mice this effect could not be detected in systemic and intralesional use of EDTA or ADR-925. ${ }^{33}$

It has been shown that dexrazoxane reversibly inhibits topoisomerase II. ${ }^{34}$ However, it is difficult to identify a mechanism by which this could occur, as these tissues are not rapidly proliferating and contain only low levels of topoisomerase II. This is also underlined by the fact that two other non-chelating catalytic agents, merbarone and aclarubicin, also inhibitors of topoisomerase II, failed to prevent anthracycline-induced extravasation injuries in animals. $^{27,33}$

\section{Pharmacokinetics/pharmacodynamics}

The pharmacokinetics of dexrazoxane initially have been studied in patients with advanced cancer having normal renal and hepatic function. Generally, the pharmacokinetics of dexrazoxane can be adequately described by an open two-compartment model with first-order elimination. Dexrazoxane has been administered as a 15 -minute infusion over a dose range of 60 to $900 \mathrm{mg} / \mathrm{m}^{2}$ with $60 \mathrm{mg} / \mathrm{m}^{2}$ of doxorubicin, and at a fixed dose of $500 \mathrm{mg} / \mathrm{m}^{2}$ with $50 \mathrm{mg} / \mathrm{m}^{2}$ doxorubicin..$^{28,35,36}$

The disposition kinetics of dexrazoxane are doseindependent, as shown by a linear relationship between the area under plasma concentration-time curves and administered doses ranging from 60 to $900 \mathrm{mg} / \mathrm{m}^{2}$. The important pharmacokinetic parameters of dexrazoxane are listed in Table 1.

Qualitative metabolism studies with dexrazoxane have confirmed the presence of unchanged drug, a diacid-diamide cleavage product, and two monoacid-monoamide ring products in the urine of animals and man.

The metabolite levels were not measured in the pharmacokinetic studies.

Urinary excretion plays an important role in the elimination of dexrazoxane. In vitro studies have shown that dexrazoxane is not bound to plasma proteins.

Accumulation of dexrazoxane has been the main point of interest in study TT04 which followed the first
Table I Summary of mean (\% coefficient of variation) dexrazoxane pharmacokinetic parameters at a dosage ratio of I0:I of dexrazoxane: doxorubin

\begin{tabular}{lll}
\hline Dose doxorubicin $\left(\mathrm{mg} / \mathrm{m}^{2}\right)$ & 50 & 60 \\
Dose dexrazoxane $\left(\mathrm{mg} / \mathrm{m}^{2}\right)$ & 500 & 600 \\
Number of subjects & 10 & 5 \\
Elimination half-life $(\mathrm{h})$ & $2.5(16)$ & $2.1(29)$ \\
Plasma clearance $\left(\mathrm{L} / \mathrm{h} / \mathrm{m}^{2}\right)$ & $7.88(18)$ & $6.25(31)$ \\
Renal clearance $\left(\mathrm{L} / \mathrm{h} / \mathrm{m}^{2}\right)$ & $3.35(36)$ & - \\
Volume of distribution $\left(\mathrm{L} / \mathrm{m}^{2}\right)^{\mathrm{a}}$ & $22.4(22)$ & $22.0(55)$ \\
\hline
\end{tabular}

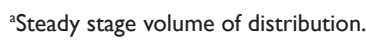

two multicenter studies (TT01 and TT02) examining the efficacy of dexrazoxane in preventing ulcerations. Levels of dexrazoxane have been measured during the 3-day scheme of application $\left(1000,1000\right.$ and $\left.500 \mathrm{mg} / \mathrm{m}^{2}\right)$ in patients suffering from an anthracycline extravasation. Six patients could be enrolled in this pharmacokinetics study. An accumulation of dexrazoxane could not be found any of these patients.

\section{Drug interactions}

There were no significant changes in the pharmacokinetics of doxorubicin $\left(50 \mathrm{mg} / \mathrm{m}^{2}\right)$ and its predominant metabolite, doxorubicinol, in the presence of dexrazoxane $\left(500 \mathrm{mg} / \mathrm{m}^{2}\right)$ in a crossover study in cancer patients. ${ }^{35}$

\section{"Drug history" in regard to extravasation}

In 2000 the first report on experimental subcutaneous (sc) injuries in mice caused by anthracycline successfully treated with dexrazoxane was published by Langer et al. ${ }^{34}$ At this time dexrazoxane was registered only as a cardio-protective agent (Zinecard $^{\circledR}$; Pfizer; Cardioxane ${ }^{\circledR}$; Novartis) against anthracycline-induced cardiotoxicity. In this paper, the authors discussed the topoisomerase II interaction as the inhibitory mechanism for its efficacy.

Also in 2000 the same authors reported two clinical cases of successful anthracycline extravasation treatment with dexrazoxane. In one case the patient experienced extravasation of epirubicin into the forearm; in the other case a total of $149 \mathrm{mg}$ of doxorubicin infiltrated subcutaneously in the chest wall due to port needle displacement. Both patients received treatment with dexrazoxane $1000 \mathrm{mg} / \mathrm{m}^{2}$ administered intravenously on day 1 and 2 , and $500 \mathrm{mg} / \mathrm{m}^{2}$ on day 3 . As a result, no surgical intervention was required and at 3 months of follow up neither of the patients showed sequelae. ${ }^{37}$ 
As a consequence of these findings a prospective clinical multi-center study was initiated.

\section{Non-clinical studies with dexrazoxane}

In an earlier series of preclinical studies, it was demonstrated that dexrazoxane administration soon after sc injection of doxorubicin, daunorubicin or idarubicin significantly reduces or prevents the formation of cutaneous lesions in mice. . $33,34,38^{2}$

\section{Clinical studies with dexrazoxane (TT0I/TT02)}

The results of two prospective multi-center. single-arm, open-label phase II/III clinical trials (TT01 and TT02) to evaluate the efficacy of iv dexrazoxane in the prevention of severe anthracycline-induced extravastion injuries have been published recently. ${ }^{28}$

The primary endpoints of these two studies were preventing patients from undergoing surgical debridement of the affected area as well as preventing development of sequelae. Secondary endpoints were prevention of postponement of the scheduled cancer treatment and evaluation of tolerability and safety of dexrazoxane. To assure "real extravasation" of anthracyclines the diagnosis of extravasation had to be confirmed by positive fluorescence microscopy in at least one biopsy of the affected region. Local cooling of the extravasation site was permitted, but not within 15 minutes before the application of dexrazoxane, whereas local treatment with dimethylsulfoxide (DMSO) or steroids were not allowed.

The 3-day treatment schedule with dexrazoxane consisted of a daily dose of $1000 \mathrm{mg} / \mathrm{m}^{2}$ on day $1-2$ and $500 \mathrm{mg} / \mathrm{m}^{2}$ on day 3 . The infusion had to be given in the opposite arm of the extravasation site and was administered as soon as possible and no longer than 6 hours after the extravasation accident.

In both studies, 54 patients, mainly women with breast cancers, were included in the final analysis. The results of the combined studies showed that in 53 of 54 (98.2\%) included patients, treatment with dexrazoxane prevented necrosis requiring surgical intervention. Only one patient $(1.8 \%)$ had to undergo surgical debridement. Thirty-eight patients (71.0\%) were able to continue their scheduled chemotherapy without delay. In addition to bone marrow suppression, as expected from the fact that the extravasation happened during a chemotherapy course, temporarily infusion site pain (19\%), mild sensory disturbance (17\%), nausea, vomiting, diarrhea, stomatitis and transient alteration in liver enzymes have been observed. All adverse events were rapidly reversible. Although difficult to access due to parallel chemotherapy application, the safety profile of dexrazoxane appears to be good. In Table 2 the sequelae of the combined studies at the 3-month follow-up are shown.

There have also been single cases of intrapleural extravasation of epirubicin caused by catheter tip misplacement that have been successfully treated with dexrazoxane. ${ }^{11}$

\section{Dosage and administration of dexrazoxane}

Dexrazoxane should be given once daily for three consecutive days. The first infusion has to be initiated as soon as possible and within the first six hours after extravasation. ${ }^{28}$

The recommended doses are as suggested by Mouridsen: ${ }^{28}$ day $1 \quad 1000 \mathrm{mg} / \mathrm{m}^{2} \quad 2000 \mathrm{mg}$ max. recommended dose day $21000 \mathrm{mg} / \mathrm{m}^{2} \quad 2000 \mathrm{mg}$ max. recommended dose day $3500 \mathrm{mg} / \mathrm{m}^{2} \quad 1000 \mathrm{mg}$ max. recommended dose

A dose reduction by $50 \%$ of dexrazoxane is necessary in patients with creatinine clearance values $<40 \mathrm{~mL} / \mathrm{min}$.

Dexrazoxane should be administered as an iv infusion over 1 to 2 hours in a large caliber vein in an extremity/area other than the one affected by the extravasation. ${ }^{39}$ Cooling procedures such as dry cold packs should be removed from the area at least 15 minutes before the infusion of dexrazoxane in order to allow sufficient blood flow in the area of extravasation. Treatment on day 2 and day 3 should start at the same time ( \pm 3 hours) as on the first day.

\section{Precautions}

When administered to patients receiving anthracyclinecontaining cytotoxic therapy, additive cytotoxicity may occur, as dexrazoxane is a cytotoxic drug itself. Therefore, hematological monitoring should be performed. Reversible elevations of liver enzymes may occur with dexrazoxane.

DMSO should not be used in patients who are receiving dexrazoxane to treat anthracycline-induced extravasation ${ }^{40}$ (see below). Women who have the potential to become

Table 2 Sequelae at 3-month follow-up in studies TTOI and TT02 28,47

\begin{tabular}{ll}
\hline Sequelae & TT0 I / TT02 (N = 54) \\
\hline None & $39(72.2 \%)$ \\
At least one & $15(27.8 \%)$ \\
Sensory disturbances & $9(16.7 \%)$ \\
Skin atrophy & $5(9.3 \%)$ \\
Pain & $10(18.5 \%)$ \\
Disfigurement & $1(1.9 \%)$ \\
Limitation of movement & $1(1.9 \%)$ \\
\hline
\end{tabular}


pregnant should be advised that dexrazoxane might cause fetal harm.

\section{Dexrazoxane and DMSO}

Before the introduction of dexrazoxane the standard treatment of anthracycline extravasation was the application of DMSO with or without cortisone. ${ }^{41,42}$ Therefore the question was raised if the addition of DMSO to dexrazoxane in extravasation injury would be beneficial. Langer et al compared the efficacy of topical DMSO and systemic dexrazoxane as monotherapy as well as in combination against anthracycline-induced ulceration in mice. ${ }^{40}$ The addition of topical DMSO to the systemic dexrazoxane treatment resulted in the occurrence of wounds in 6 of $9(66 \%)$ of the mice compared to none for dexrazoxane alone. The authors concluded that the addition of topical DMSO to iv dexrazoxane treatment resulted in decreased efficacy. Although the study was conducted in animals, the results do not support the use of DMSO in combination with dexrazoxane.

\section{Dexrazoxane and liposomal anthracyclines}

In the study by Mouridsen only one patient received liposomal anthracycline, who did respond but not as well as the other patients. ${ }^{28}$ From this single case it is impossible to draw any firm conclusions; however it is conceivable that dexrazoxane may not be as effective in these patients, as the initial injury is masked by the liposomal envelope surrounding the anthracycline.

In case reports about extravasations of liposomal anthracyclines, their ulcerative potency is described as being much weaker than that of non-liposomal anthracyclines. The actions taken after extravasation did not include the use of dexrazoxane. ${ }^{43,44}$

Nevertheless, the ulcerative potential of liposomal anthracyclines might be a matter of the amount of extravasated agent, as small amounts did not cause ulcers (irritant) but larger quantities of extravasated liposomal cytotoxic drugs caused severe tissue defects (vesicant). ${ }^{45}$

As a possible cause of this reduced harmfulness, an evacuation of liposomal drugs via the lymphatic system has been proved in mice models. ${ }^{46}$

\section{Conclusions}

Dexrazoxane is an important development in the management of anthracycline extravasation. In case of a positively identified anthracycline extravasation it should be available within 6 hours and administered in the licensed 3-day course. However, the introduction of this new antidote needs to be audited for its efficacy in actual practice and further research work should be performed to better refine and develop its use.

\section{Disclosures}

The authors disclose no conflicts of interest.

\section{References}

1. Zatkone Puskas G. [The significance of extravasation in oncological care]. Magy Onkol. 2008;52:75-80.

2. Monstrey SJ, Mullick P, Narayanan K, et al. Hyperbaric oxygen therapy and free radical production: an experimental study in doxorubicin (Adriamycin) extravasation injuries. Ann Plast Surg. 1997;38: 163-168.

3. Kane RC, McGuinn WD Jr, Dagher R, et al. Dexrazoxane (Totect): FDA review and approval for the treatment of accidental extravasation following intravenous anthracycline chemotherapy. Oncologist. 2008;13:445-50.

4. Parsons JL Jr. TopoTarget responds. Clin J Oncol Nurs. 2007; 11:789.

5. Schrijvers DL. Extravasation: a dreaded complication of chemotherapy. Ann Oncol. 2003;14(Suppl 3):iii26-30.

6. Cox K, Stuart-Harris R, Abdini G, et al. The management of cytotoxicdrug extravasation: guide-lines drawn up by a working party for the Clinical Oncological Society of Australia. Med J Aust. 1988;148: 185-189.

7. Jordan K, Behlendorf T, Surov A, et al. Venous access ports: frequency and management of complications in oncology patients. Onkologie. 2008;31:404-410.

8. Held-Warmkessel J. Accidental anthracycline extravasation. Nursing. 2007;37:72.

9. Langstein HN, Duman H, Seelig D, et al. Retrospective study of the management of chemotherapeutic extravasation injury. Ann Plast Surg. 2002;49:369-74.

10. Schulmeister L: Managing vesicant extravasations. Oncologist. 2008; 13:284-288

11. Uges JW, Vollaard AM, Wilms EB, et al. Intrapleural extravasation of epirubicin, 5-fluouracil, and cyclophosphamide, treated with dexrazoxane. Int J Clin Oncol. 2006;11:467-470.

12. Langer SW. Treatment of anthracycline extravasation from centrally inserted venous catheters. Oncol Rev. 2008;2:114-116.

13. Jordan K, Grothe W, Schmoll HJ. [Extravasation of chemotherapeutic agents: prevention and therapy]. Dtsch Med Wochenschr. 2005;130: 33-37.

14. Susser WS, Whitaker-Worth DL, Grant-Kels JM. Mucocutaneous reactions to chemotherapy. J Am Acad Dermatol. 1999;40:367-398; quiz 399-400.

15. Dorr RT. Antidotes to vesicant chemotherapy extravasations. Blood Rev. 1990;4:41-60.

16. Bertelli G. Prevention and management of extravasation of cytotoxic drugs. Drug Saf. 1995;12:245-255.

17. Goolsby TV, Lombardo FA. Extravasation of chemotherapeutic agents: prevention and treatment. Semin Oncol. 2006;33:139-143.

18. Reeves D. Management of anthracycline extravasation injuries. Ann Pharmacother. 2007;41:1238-1242.

19. Ener RA, Meglathery SB, Styler M. Extravasation of systemic hematooncological therapies. Ann Oncol. 2004;15:858-862.

20. Schulmeister L, Gobel BH. Symptom management issues in oncology nursing. Nurs Clin North Am. 2008;43:205-220.

21. Schulmeister L. Infiltration and extravasation. Am J Nurs. 2007; 107:16.

22. Preuss P, Partoft S. Cytostatic extravasations. Ann Plast Surg. 1987; 19:323-329. 
23. Kaehler KC, Mustroph D, Hauschild A. Current recommendations for prevention and therapy of extravasation reactions in dermato-oncology. J Dtsch Dermatol Ges. 2008;3:150-159.

24. Damert HG, Lenz-Scharf O, Altmann S, et al. [Soft-tissue defects on the dorsum of the hand by extravasation of the cytostatic agents: surgical options of treatment]. Handchir Mikrochir Plast Chir. 2007; 39:409-413.

25. Scuderi N, Onesti MG. Antitumor agents: extravasation, management, and surgical treatment. Ann Plast Surg. 1994;32:39-44.

26. Heitmann C, Durmus C, Ingianni G. Surgical management after doxorubicin and epirubicin extravasation. J Hand Surg [Br]. 1998;23: 666-668.

27. Hasinoff BB. The use of dexrazoxane for the prevention of anthracycline extravasation injury. Expert Opin Investig Drugs. 2008;17: 217-223.

28. Mouridsen HT, Langer SW, Buter J, et al. Treatment of anthracycline extravasation with Savene (dexrazoxane): results from two prospective clinical multicentre studies. Ann Oncol. 2007;18:546-550.

29. Ward MS. Re: Totect: a new agent for treating anthracycline extravasation. Clin J Oncol Nurs. 2007;11:613; author reply 613.

30. El-Saghir N, Otrock Z, Mufarrij A, et al. Dexrazoxane for anthracycline extravasation and GM-CSF for skin ulceration and wound healing. Lancet Oncol. 1998;5:320-321.

31. Hasinoff BB. Chemistry of dexrazoxane and analogues. Semin Oncol. 1998;25:3-9.

32. Hasinoff BB. The interaction of the cardioprotective agent ICRF-187 [+)-1,2-bis(3,5-dioxopiperazinyl-1-yL)propane); its hydrolysis product (ICRF-198); and other chelating agents with the $\mathrm{Fe}(\mathrm{III})$ and $\mathrm{Cu}(\mathrm{II})$ complexes of adriamycin. Agents Actions. 1989;26:378-385.

33. Langer SW, Sehested M, Jensen PB. Dexrazoxane is a potent and specific inhibitor of anthracycline induced subcutaneous lesions in mice. Ann Oncol. 2001;12:405-410.

34. Langer SW, Sehested M, Jensen PB. Treatment of anthracycline extravasation with dexrazoxane. Clin Cancer Res. 2000;6:3680-3686.
35. Chow WA, Synold TW, Tetef ML, et al. Feasibility and pharmacokinetic study of infusional dexrazoxane and dose-intensive doxorubicin administered concurrently over $96 \mathrm{~h}$ for the treatment of advanced malignancies. Cancer Chemother Pharmacol. 2004;54:241-248.

36. Cusack BJ, Musser B, Gambliel H, et al. Effect of dexrazoxane on doxorubicin pharmacokinetics in young and old rats. Cancer Chemother Pharmacol. 2003;51:139-146.

37. Langer SW, Sehested M, Jensen PB, et al. Dexrazoxane in anthracycline extravasation. J Clin Oncol. 2000;18:3064.

38. Jensen JN, Lock-Andersen J, Langer SW, et al. Dexrazoxane-a promising antidote in the treatment of accidental extravasation of anthracyclines. Scand J Plast Reconstr Surg Hand Surg. 2003;37:174-175.

39. Wengstrom Y, Margulies A: European Oncology Nursing Society extravasation guidelines. Eur J Oncol Nurs. 2008;12:357-361.

40. Langer SW, Thougaard AV, Sehested M, et al. Treatment of anthracycline extravasation in mice with dexrazoxane with or without DMSO and hydrocortisone. Cancer Chemother Pharmacol. 2006;57:125-128.

41. Bos AM, van der Graaf WT, Willemse PH. A new conservative approach to extravasation of anthracyclines with dimethylsulfoxide and dexrazoxane. Acta Oncol. 2001;40:541-542.

42. Albanell J, Baselga J. Systemic therapy emergencies. Semin Oncol. 2000;27:347-361

43. Madhavan S, Northfelt DW. Lack of vesicant injury following extravasation of liposomal doxorubicin. J Natl Cancer Inst. 1995;87:1556-1557.

44. Cabriales S, Bresnahan J, Testa D, et al. Extravasation of liposomal daunorubicin in patients with AIDS-associated Kaposi's sarcoma: a report of four cases. Oncol Nurs Forum. 1998;25:67-70.

45. Lokich J. Doxil extravasation injury: a case report. Ann Oncol. 1999; 10:735-736

46. Allen TM, Hansen CB, Guo LS. Subcutaneous administration of liposomes: a comparison with the intravenous and intraperitoneal routes of injection. Biochim Biophys Acta. 1993;1150:9-16.

47. Langer SW. Dexrazoxane for anthracycline extravasation. Expert Rev Anticancer Ther. 2007; 7:1081-1088.
Therapeutics and Clinical Risk Management

\section{Publish your work in this journal}

Therapeutics and Clinical Risk Management is an international, peerreviewed journal of clinical therapeutics and risk management, focusing on concise rapid reporting of clinical studies in all therapeutic areas outcomes, safety, and programs for the effective, safe, and sustained use of medicines. This journal is indexed on PubMed Central, CAS,

\section{Dovepress}

EMBase, Scopus and the Elsevier Bibliographic databases. The manuscript management system is completely online and includes a very quick and fair peer-review system, which is all easy to use. Visit http://www.dovepress.com/testimonials.php to read real quotes from published authors. 